\title{
Algumas questões decorrentes da reintrodução do Aedes aegypti no Brasil
}

\section{Pedro Paulo Chieffi}

A reintrodução do Aedes aegypti em inúmeros pontos do território nacional suscita diversas questões de ordem sanitária que merecem atenção especial dos responsáveis pelo planejamento de ações de Saúde Pública, nos âmbitos federal e estadual.

Recuando algumas décadas em nossa história, percebe-se que a erradicação do $A$. aegypti que se tornou um dos objetivos nacionais através do Decreto no 8.675, de 4/2/1942, já era, desde 1934, extra-oficialmente, uma das finalidades precípuas do serviço de combate à febre amarela. Sua reintrodução, inicialmente em Belém em 19671, a seguir, em diversas outras localidades e, por fim, nos últimos anos, em grandes centros urbanos como Rio de Janeiro e São Paulo, além de várias dezenas de municípios espalhados por diversos Estados, demonstra a ineficácia de campanhas de erradicação isoladas.

Embora espécie alóctone para o continente americano, uma vez que originária da África ${ }^{4}$, o $A$. aegypti encontrou condições muito favoráveis ao seu desenvolvimento e colonização em terras da América, tornando-se problemática sua completa extinção, a menos que campanha nesse sentido seja desencadeada em todas as áreas afetadas.

Fatores associados ao modo de organização das populações humanas têm papel decisivo no estabelecimento de criadouros de $A$. aegypti, junto aos núcleos populacionais urbanos. A forma complexa e caótica pela qual se processa a urbanização nos países de capitalismo tardio ou dependente, onde o progresso obedece inexoravelmente aos interesses ditados pela necessidade de reprodução do capital, em detrimento do bem-estar da população, cria condições extremamente favoráveis ao estabelecimento de nichos ecológicos que se constituem em excelentes criadouros para o A. aegypti. A necessidade de reciclar rapidamente os bens de -consumo duráveis, cuja produção representa a parcela mais destacada do setor industrial da economia de países de industrialização tardia como o Brasil, condiciona a existência de grandes quantidades de depósitos de materiais usados ou em desuso, muitas vezes expostos às intempéries e Cadernos de Saúde Pública, R.J., 1 (3): 385-387, jul/set, 1985.
*Instituto Adolfo Lutz e Faculdade de Ciências Médicas da Santa Casa de Misericórdia de São Paulo.
Recebido para publicação em $22 / 07 / 85$ 
que, ao coletarem água proveniente das chuvas, constituemse em inúmeros e inexpugnáveis criadouros de mosquitos. Em particular, os depósitos de pneus usados, que têm sido reciclados para uso industrial, fornecem nichos seguros para a criação do $A$. aegypti, como indica a reintrodução desse mosquito em El Salvador, em $1965^{5}$, além de seu encontro freqüente, em nosso meio, ultimamente, nesse tipo de estabelecimento de comércio.

Outros pontos relacionados à epidemiologia da febre amarela devem, também, ser lembrados e constituir objeto de apreciação por parte dos encarregados das medidas para impedir a reintrodução da endemia amarílica, em áreas urbanas brasileiras. Quando, no começo do século, iniciou-se a luta contra a febre amarela através do combate ao seu transmissor, percebeu-se que não era necessário exterminálo completamente para interromper a transmissão em áreas urbanas. Mantendo-se o índice de infestação domiciliar por $A$. aegypti em niveis inferiores a $5 \%$, desapareceriam os casos urbanos de febre amarela ${ }^{5}$. Presentemente, dispõem-se de índices mais precisos para avaliar o risco de transmissão urbana da febre amarela e uma das tarefas urgentes em nosso meio é sua determinação, para aquilatar o potencial de ocorrência de casos de infecção pelo vírus amarílico em nossas áreas metropolitanas. Paralelamente, dever-se-ia estudar a suscetibilidade das cepas de $A$. aegypti que se encontram atualmente em muitos municípios brasileiros, para determinar sua real importância como transmissores dos vírus da febre amarela e do dengue.

A possibilidade da ocorrência de epidemias de dengue é outro aspecto que não pode ser desprezado na avaliação dos riscos a que permanecem expostas as populações das áreas reinfestadas pelo $A$. aegypti. O surto dessa virose, ocorrido na região das Antilhas e na Venezuela, entre 1963 e 1965, e a pandemia que grassou por toda a América Central, em 19773 , assim como os episódios mais recentes da Colômbia e de Cuba, onde muitos milhares de casos foram verificados, são exemplos insofismáveis de que o dengue ocorre somente nas áreas em que o $A$. aegypti está presente.

No Brasil, o único surto de dengue bem documentado ocorreu em Boa Vista, capital de Roraima, em período compreendido pelo final de 1981 e início de $1982^{2}$. Calcula-se que, nessa época, tenham acontecido cerca de 7.000 casos da virose, tendo sido identificados, em amostras da população, vírus dos tipos 1 e 4 . Anteriormente, nos primeiros anos da década de 50 , em inquérito soroepidemiológico realizado pelo Instituto Evandro Chagas, alguns indivíduos já tinham sido encontrados com anticorpos antidengue, na Amazônia ${ }^{2}$. Estes registros, além do surto bem determinado de Boa Vista, constituem talvez os únicos 
dados confiáveis acerca da ocorrência de dengue no Brasil. Torna-se, desta maneira, prioritária a realização de inquéritos soroepidemiológicos visando aferir o contacto prévio com o vírus do dengue em habitantes das áreas atualmente infestadas pelo $A$. aegypti, uma vez que em certos pacientes, já sensibilizados pelos antígenos virais, podem verificar-se quadros de maior gravidade, caso ocorra nova infecção.

\section{REFERÊNCIAS BIBLIOGRÁFICAS}

1. FRANCO, O. História da febre amarela no Brasil. Rev. Brasil. Malar. D. trop. 21: 317-520, 1969.

2. OSANAI, C.H. et alii. Surto de dengue em Boa Vista, Roraima. Nota prévia. Rev. Inst. Med. trop. S. Paulo, 25: 53-4, 1983.

3. PAN AMERICAN HEALTH ORGANIZATION - Dengue in the Caribbean, 1977. Scientific Publication, no 375, Washington, 1977.

4. SOPER, F.L. Erradicación en las Américas de los invasores africanos Aedes aegypti y Anopheles gambiae. Bol. Of. Sanit. Panam., 55: 259-66, 1963.

5. SOPER, F.L. El Aedes aegypti y la fiebre amarilla. Bol. Of. Sanit. Panam., 64: 187-96, 1968. 